\title{
Effect of Pre-test Genetic Counseling for Deaf Adults on Knowledge of Genetic Testing
}

\author{
Erin E. Baldwin • Patrick Boudreault • Michelle Fox • \\ Janet S. Sinsheimer $\cdot$ Christina G. S. Palmer
}

Received: 23 March 2011 /Accepted: 21 July 2011 /Published online: 5 August 2011

(C) The Author(s) 2011.This article is published with open access at Springerlink.com

\begin{abstract}
Empirical data on genetic counseling outcomes in the deaf population are needed to better serve this population. This study was an examination of genetics knowledge before and after culturally and linguistically appropriate pre-test genetic counseling in a diverse deaf adult sample. Individuals $\geq 18$ years old with early-onset sensorineural deafness were offered connexin-26/30 testing and genetic counseling. Participants completed questionnaires containing 10 genetics knowledge items at baseline and following pre-test genetic counseling. The effects of genetic
\end{abstract}

E. E. Baldwin • C. G. S. Palmer ( $₫)$

Department of Psychiatry \& Biobehavioral Sciences, UCLA,

760 Westwood Plaza, Room 47-422,

Los Angeles, CA 90095, USA

e-mail: cpalmer@mednet.ucla.edu

P. Boudreault

Department of Deaf Studies, CSUN,

Northridge, CA, USA

M. Fox

Department of Pediatrics, UCLA,

Los Angeles, CA, USA

J. S. Sinsheimer • C. G. S. Palmer

Department of Human Genetics, UCLA,

Los Angeles, CA, USA

J. S. Sinsheimer

Department of Biostatistics, UCLA,

Los Angeles, CA, USA

\section{J. S. Sinsheimer}

Department of Biomathematics, UCLA,

Los Angeles, CA, USA

J. S. Sinsheimer • C. G. S. Palmer

Center for Society and Genetics, UCLA,

Los Angeles, CA, USA counseling, prior beliefs about etiology, and participant's preferred language on genetics knowledge scores were assessed $(n=244)$. Pre-test genetic counseling $(p=.0007)$, language $(p<.0001)$, prior beliefs $(p<.0001)$, and the interaction between counseling and beliefs $(p=.035)$ were predictors of genetics knowledge. American Sign Language (ASL)-users and participants with "non-genetic/unknown" prior beliefs had lower knowledge scores than English-users and participants with "genetic" prior beliefs, respectively. Genetics knowledge improved after genetic counseling regardless of participants' language; knowledge change was greater for the "non-genetic/unknown" beliefs group than the "genetic" beliefs group. ASL-users' lower knowledge scores are consistent with evidence that ethnic and cultural minority groups have less genetics knowledge, perhaps from exposure and access disparities. Culturally and linguistically appropriate pre-test genetic counseling significantly improved deaf individuals' genetics knowledge. Assessing deaf individuals' prior beliefs is important for enhancing genetics knowledge.

Keywords Genetic counseling · Connexin-26 - GJB2 . Deaf - Genetic testing - American Sign Language .

Deafness $\cdot$ Minority $\cdot$ Genetics knowledge

\section{Introduction}

Recent studies have demonstrated that some deaf and hardof-hearing individuals are interested in learning why they are deaf (Boudreault et al. 2010; Burton et al. 2006; Withrow et al. 2009a, b); and with the widespread availability of genetic testing for deafness and increasing availability of information about what genetic counseling and testing can offer in general, it is likely the number of deaf clients seeking genetics services will increase. As with 
any genetic testing, pre-test genetic counseling is an important element of the process for ensuring that individuals understand relevant genetics concepts, and the benefits and limitations of genetic testing for deaf genes (Brunger et al. 2000; Palmer et al. 2009). Parents of deaf infants have been found to have good genetics knowledge outcomes following pre-test genetic counseling for connexin-26 (GJB2 [OMIM 220290]) and connexin-30 (GJB6 [OMIM 612645]) genetic testing (Palmer et al. 2009). However, the efficacy of pre-test genetic counseling on knowledge outcomes has not yet been studied for deaf and hard-of-hearing adults. This is a significant issue that needs to be addressed because the unique language and culture shared by many deaf and hardof-hearing individuals challenge the norms for both acquisition and provision of genetics information which could impact the effectiveness of pre-test genetic counseling in this population.

In this article, the term Deaf (with a capital D) is used to refer to individuals who are members of the Deaf community, a distinct cultural group. The term Deaf is distinct from deaf (with a lower case d), which refers simply to an audiologic phenotype; individuals within the Deaf community may be deaf or hard-of-hearing (Senghas and Monaghan 2002). The Deaf community has a distinct culture with its own beliefs, customs, attitudes, language, and behavioral norms. Specifically, this culturally collective group does not view being deaf as a medical condition that requires a treatment or cure, but, rather, as a trait or characteristic of human diversity that is important to their culture (Padden and Humphries 1988).

American Sign Language (ASL) is the primary language for culturally Deaf individuals within the U.S. Deaf community and English is usually their second language. However, there is variability in language and modality use within the deaf and hard-of-hearing population (Wilcox 1989), such that some individuals may opt to use spoken English, a combination of ASL and English, a form of signed English, or, in some rare instances, a home sign (a unique signed language developed and used within the home of the deaf individual) (Van Deusen-Phillips et al. 2001). The language a deaf or hard-ofhearing individual uses depends on a number of factors, including their cultural affiliation, their experiences interacting with deaf and hearing individuals, the audiologic level of their hearing condition, their upbringing, and their school setting (Padden and Humphries 1988).

To date, there have been no studies on genetics knowledge in the deaf population. However, as with other linguistic and cultural minority groups, institutional, socio-cultural, and educational factors likely affect signed language users' knowledge of genetics concepts and terms. Most health information is configured for hearing individuals and is relayed in spoken or written English. Spoken English poses a significant challenge to the millions of Americans who are deaf or hard-of-hearing, but both print and spoken English pose a significant challenge for many Deaf individuals whose native language is ASL. ASL has a distinct grammar and word order, and it differs significantly from English or signed English. Therefore, English is often experienced as a second language for many Deaf individuals; and because information is often conveyed in written or spoken English, ASL-users have limited access to incidental health information, including genetics information, that is readily available to hearing individuals through channels such as the mass and social media, internet, friends, and the community (Harmer 1999; Israel et al. 1992).

ASL is a productive and highly inflective language which can generate any complex concept in genetics discourse, and genetics terminology in ASL is used by Deaf academics. However, academic ASL terminology is not widespread among general ASL users (Ross and Berkowitz 2008), and educational curricula for deaf and hard-of-hearing individuals may fail to incorporate a comprehensive education in the basic sciences, including biology (Harmer 1999). Thus signs for many genetics concepts are not yet common or recognized among ASL-users. The absence of consensus on standardized signs for genetics concepts may lead to limited opportunity for ASL-users to be exposed to the latest information on genetic mechanisms, genetic etiology and genetic testing, which could in turn affect the knowledge base of general genetics concepts within the deaf population.

Perceptions of cultural insensitivity or lack of information among hearing professionals regarding the Deaf community can be important factors in Deaf individuals' genetics knowledge and understanding as well. The Deaf community has endured a history of discrimination, non-acceptance, audism, and even eugenics (Lane 1999; Schuchman 2004). As a consequence, Deaf individuals may approach the genetics community with distrust which could negatively affect their interest in learning genetics information or receiving genetics services. Contributing to this is the common perception within the medical community that deaf people have a disability which needs intervention and remediation. This perception may translate into culturally insensitive medical care for deaf or hard-of-hearing individuals, leading to reduced rapport (Padden and Humphries 1988). Compounding these issues is the unfamiliarity and limited experience many health care providers, including genetic counselors, have in working with signed language users (Enns et al. 2010) resulting in ASLusers' frustration with health care professionals who are not sensitive to providing health information in a culturally and linguistically appropriate manner (Steinberg et al. 2006). For example, a study of 45 deaf women found not only that they had limited health knowledge relating to cancer screening, but some of the deaf women actually avoided health care services due to frustration over communication barriers or cultural ignorance on the part of their health care provider (Steinberg et al. 2002). 
Variable English proficiency, poor provider-patient communication, and fewer health education opportunities than hearing individuals collectively affect deaf individuals' understanding of health and illness, access to care and information, and awareness and utilization of treatment options (Harmer 1999); as a result, the deaf population experiences significant health disparities (Barnett and Franks 2002; Orsi et al. 2007; Tamaskar et al. 2000). However, use of culturally and linguistically sensitive approaches for providing health care has been shown to increase health knowledge in the deaf population regarding tobacco-related diseases (Berman et al. 2011) and cervical cancer (Choe et al. 2009), and to produce significant increases in understanding of prostate and testicular cancer that remained present two months after receipt of information (Folkins et al. 2005).

These studies not only suggest that culturally and linguistically tailored genetic counseling may be an important component for enhancing deaf individuals' genetics knowledge outcomes, but also enhancing genetics knowledge could be important for reducing health disparities experienced by this group and improving their overall health and well-being. For example, genetic counseling can aid in the understanding of the genetic heterogeneity and general etiologies that may result in a person being deaf. In some instances, identifying a hereditary reason that one is deaf may be beneficial for medical management in situations where the genetic etiology may result in medical complications if unrecognized [e.g., cardiac manifestations in Jervell and Lange-Nielsen Syndrome (Schwartz et al. 2006)]. Furthermore, enhanced self-knowledge from genetic information for non-disease traits has been shown to impact health outcomes (Gordon et al. 2005) and psychological well being (Gordon et al. 2005; Sankar et al. 2006). Because deafness is considered a non-medical trait by many individuals, enhancing deaf individuals' knowledge about why they are deaf may have a variety of beneficial outcomes including improved health and well-being. Current literature on effects of enhanced self-knowledge in the deaf population is limited, however, and analyses of these types of outcomes are the focus of our future manuscripts.

Finally, genetic counseling can provide deaf and hard-ofhearing individuals with an opportunity to learn about clinical genetic services in general and the utility of genetic testing and screening for conditions unrelated to being deaf, such as cancer, which may be revealed through careful assessment of the individual's family history. Studies have demonstrated that improving cancer genetics knowledge via genetic counseling and testing has many benefits, such as cancer prevention (Rebbeck et al. 2004), increased screening (Hadley et al. 2004), and more appropriate use of healthcare resources, including the promotion of genetic counseling for those who are at inherited risk of cancer (Daly et al. 2006), and reduction in interest in genetic testing among those in low risk groups (Green et al. 2004). Thus, increasing genetics knowledge in the deaf population is an important element in reducing health disparities.

Numerous studies have demonstrated that genetic counseling can enhance genetics knowledge outcomes (Cabrera et al. 2010; Hwa et al. 2010; Kelly et al. 2004; Lerman et al. 1997). Factors such as age and education level (Cabrera et al. 2010), family history (Hiraki et al. 2009; MacNew et al. 2010), beliefs related to causality or etiology (Kash et al. 1995), likelihood of a genetic etiology (Hiraki et al. 2009), disease status (Kelly et al. 2004; Pieterse et al. 2011), and risk perception (Cabrera et al. 2010) are important covariates of genetics knowledge and understanding. In some studies, these factors have been shown to be important for identifying subgroups that may particularly benefit from genetic counseling (Green et al. 2004; Hiraki et al. 2009; Lerman et al. 1997; Pal et al. 2010). In addition, studies have demonstrated minority status is a predictor of genetics knowledge and that individuals belonging to cultural and linguistic minority groups often have lower baseline levels of genetics knowledge (Halbert et al. 2005; Kinney et al. 2010; MacNew et al. 2010).

Studies specifically examining effectiveness of genetic counseling to enhance genetics knowledge outcomes in cultural and linguistic minority groups are beginning to emerge (Halbert et al. 2010; Pal et al. 2010; Sussner et al. 2010). While a recent study found that deaf individuals may have some familiarity with the concept of genetic counseling (Middleton et al. 2010a), there is a paucity of data on the effectiveness of genetic counseling to enhance genetics knowledge outcomes in the deaf and hard-of-hearing population, including the Deaf community.

\section{Purpose of the Study}

This study begins to fill the literature gap on genetic counseling for the deaf population by providing empirical data on genetics knowledge, factors associated with genetics knowledge, and the effectiveness of pre-test genetic counseling on genetics knowledge outcomes in a large culturally and linguistically diverse deaf and hard-ofhearing sample. This article includes a description of a culturally and linguistically tailored approach to providing genetic counseling and testing to deaf and hard-of-hearing adults. There were two main research questions: (1) Does pre-test genetic counseling enhance deaf and hard-ofhearing individuals' knowledge about genetics and genetic testing for deaf genes? and (2) Is genetics knowledge associated with deaf individuals' language or prior beliefs about the reason for being deaf? Although this study is specific to pre-test genetic counseling for deaf genes, the results may be useful for considering in the context of 
genetic counseling and testing for non-deaf related reasons in the deaf population, and in other linguistic and cultural minority communities.

\section{Methods}

\section{Background: Deaf Genetics Project}

The Deaf Genetics Project is a collaborative research project between California State University Northridge (CSUN) and the University of California Los Angeles (UCLA). The project's goal is to examine the impact of genetic counseling and genetic testing for deaf genes on attitudes toward genetic testing, genetics knowledge and understanding, cultural affiliation, and psychological and behavioral outcomes within the deaf or hard-of-hearing population, using a prospective, longitudinal study design. This article focuses on findings regarding the impact of pretest genetic counseling on participants' genetics knowledge.

Deaf, hard-of-hearing, and hearing researchers from a variety of disciplines, including Deaf Studies, Linguistics, Sign Language Interpreting, Genetics, Genetic Counseling, Audiology, and Statistics worked together as members of the core research team to design a culturally and linguistically appropriate genetic counseling and testing model. All members of the research team, including the genetic counselors, attended approximately 10 hours of Deaf cultural sensitivity workshops to enhance their genetic counseling interactions with deaf and hard-of-hearing individuals. Cultural and linguistic diversity in the research team was felt to be an essential step for integrating the Deaf cultural perspective, the hearing cultural perspective, the academic cultural perspective, and the community service perspective into the design and implementation of culturally and linguistically appropriate genetic counseling.

\section{Participants and Procedures}

Deaf or hard-of-hearing individuals were eligible to participate in this study if they had early-onset (defined as age 6 years or younger) sensorineural deafness of an unknown etiology and were at least 18 years old. Participants were recruited over a period of 25 months through deaf or hard-of-hearing organizations, community events, conferences, support groups, and audiology clinics in Los Angeles, Alameda, and San Bernardino counties of California. A study website (www.deafgeneticsproject.org), brochure, postcard, advertisements, and in-person presentations were developed and used for recruitment. Recruitment materials indicated the following: the focus of the study was on genetic counseling and genetic testing for two genes called connexin-26 and connexin-30 that might explain why an individual is deaf; sharing their experience with genetic counseling and genetic testing could help society understand how genetic testing can impact deaf and hardof-hearing individuals; the research team was composed of Deaf, hard-of-hearing, and hearing individuals; and the study was not intended to cure deafness or to affect an individual's hearing. All materials were culturally and linguistically appropriate with use of visual aids, layperson's terms in written English, and information provided in ASL. Interested individuals were invited to contact project personnel via point-to-point webcam communication (e.g., videophone), telecommunication devise for the deaf (e.g., TTY), email, or voice telephone.

Individuals determined initially eligible based upon a brief screening questionnaire were scheduled for an audiology evaluation to confirm the presence of sensorineural deafness (defined for this study as a pure tone average of $35 \mathrm{db}$ or greater in both ears). This step was considered essential to ensure that connexin-26 and connexin-30 genetic testing was offered only to individuals for whom it was potentially relevant. To facilitate participation, individuals could select one of four locations for their participation (University of California Los Angeles, California State University Northridge, California School for the Deaf-Fremont, California School for the Deaf-Riverside), which included three deaf community-based locations.

Participants with confirmed sensorineural deafness were then offered a pre-test genetic counseling session with one of four project board-certified genetic counselors to discuss connexin-26 and connexin-30 genetic testing. During the semi-structured pre-test genetic counseling sessions, the genetic counselor queried the participant about deaf, hard-of-hearing, and hearing relatives using a standardized protocol and generated a detailed 3generation pedigree. The genetic counselor provided information on the general etiologies of deafness, and basic genetics concepts were reviewed and discussed in the context of the participant's family history. General information about genetic testing and genetic services for deaf adults was provided. During the pre-test genetic counseling session, emphasis was placed on information about connexin-26, connexin-30, and their autosomal recessive mechanism of inheritance. The limitation that the study was offering genetic testing for only two genes and the considerable genetic heterogeneity demonstrated in the deaf population were discussed in detail. The genetic counselor engaged the participants in a discussion of the benefits, risks, and limitations of genetic testing for connexin-26 and connexin-30 in the context of the participant's personal and family history. Genetic counseling sessions were standardized as much as possible, using a genetic counseling notebook with visual aids and identifying key concepts to routinely discuss. 
Immediately following pre-test genetic counseling, participants were offered sequencing of the $G J B 2$ gene for connexin-26 and testing for delGJB6-D13S1830, the common deletion in the GJB6 gene for connexin-30 (del Castillo et al. 2002). Participants opting to pursue genetic testing then returned for a post-test genetic counseling session at which time their genetic test results were disclosed and discussed in the context of their family history and personal motivations for testing. During the post-test genetic counseling session, the option for clinical genetics services was discussed with the participant, and contact information for local genetics clinics was offered.

An important element of our culturally and linguistically appropriate genetic counseling sessions was the integral inclusion of certified ASL/English sign language interpreters. Three certified ASL/English interpreters were members of the project staff, and an interpreter was available for all participants during the course of the research protocol unless the participant opted to use spoken English without an interpreter. These ASL/English interpreters were certified by the Registry of Interpreters for the Deaf (RID), which provides interpreters with a code of conduct and ethical guidelines (Registry of Interpreters for the Deaf 2005). They were bilingual and bicultural, and their presence during sessions helped ensure clear and appropriate communication between the genetic counselor and the deaf participant (Professional Standards Committee Registry of Interpreters for the Deaf 2007). Because genetics terminology and concepts in ASL are not widespread, the staff interpreters and Deaf researchers consulted with several Deaf and hearing academics who had familiarity with this ASL terminology to ensure that appropriate signs were used. In addition, the staff interpreters were trained extensively in the relevant genetics topics to further facilitate accurate and consistent explanations of complex genetic information. The staff interpreters were not limited to interpreting roles but also functioned as the primary contact for many of the deaf participants in the project, helping to demonstrate the project's commitment to cultural and linguistic sensitivity.

Through the course of the study, participants were asked to complete four questionnaires. All four questionnaires were nearly identical so items could be assessed in a longitudinal framework. They queried a variety of factors, including demographic characteristics, attitudes toward genetic testing, genetics knowledge and understanding, cultural affiliation, and psychological and behavioral functioning. The first questionnaire, referred to as the baseline questionnaire, was completed immediately following the audiology evaluation. The second questionnaire, referred to as the pre-test counseling questionnaire, was completed immediately following the pre-test genetic counseling appointment. The third and fourth questionnaires were completed one month and six months following the disclosure of the genetic test results, respectively.

Questionnaires were translated into ASL using a translation-back translation procedure in which a bilingual ASL/English Deaf individual translated the original English version into ASL, another bilingual ASL/English individual back-translated the ASL version to English, and any inconsistencies in meaning were identified and resolved (Brislin 1970; Samady et al. 2008). Questionnaires were available to participants in English text (paper and online versions), ASL (online video streaming), and an online dual language format of both English text and ASL video.

A subset of 30 subjects were asked to complete an additional questionnaire following the audiology appointment but prior to the pre-test genetic counseling appointment (referred to as the "equivalence" questionnaire) for the purpose of comparing the equivalence of the English text version to the ASL video version of the questionnaire items. The equivalence questionnaire did not include demographic questions but was otherwise identical to the baseline questionnaire. Fifteen individuals completed the baseline questionnaire in English and the equivalence questionnaire in ASL, and the other fifteen individuals completed the questionnaires in reverse language order. The main focus of this article is on data collected from the baseline and pre-test counseling questionnaires.

The study was approved by the CSUN and UCLA institutional review boards. Informed consent was obtained for all study participants, and all potential participants were informed that genetic counseling and genetic testing were also available outside of the study. All research personnel obtained training on Health Insurance Portability and Accountability Act (HIPAA) privacy rules, which provided additional protection to participants when a third party (i.e., an interpreter) was present during genetic counseling sessions.

\section{Measures}

\section{Genetics Knowledge}

A set of ten true/false items were included on the baseline and pre-test genetic counseling questionnaires to assess knowledge of deaf genetics, recessive inheritance, and genetic testing in general (Table 4). Several items were adapted from a previous study examining genetic testing for deafness (Palmer et al. 2009). The remaining items were developed and pilot-tested with a culturally diverse sample of 12 deaf and hard-ofhearing individuals for clarity and comprehension, and revisions were made as needed prior to use in this study. Baseline and pre-test genetic counseling knowledge scores were generated for each participant based upon the number of correct responses for these questions. Scores could range from 0 (no correct responses) to 10 (all correct responses). 


\section{Language}

Participants' language was classified into one of four categories based on their language use during interactions with hearing audiology and genetic counseling project staff: ASL with interpreter present, ASL and English combination with interpreter present, English with no interpreter, and other (e.g., Signed English). Note that interactions with staff interpreters for scheduling appointments or addressing other project-related questions could occur directly in the participants' primary language without the presence of a third party, e.g., genetic counselor.

\section{Prior Beliefs about Etiology}

Prior beliefs were assessed from the baseline questionnaire. Individuals were asked to select the most likely reason they are deaf from a list of 6 options: "It is genetic, because other people in my family are deaf/hard-of-hearing"; "It is genetic, even though no one else in the family is deaf/hardof-hearing"; "Something happened when my mother was pregnant with me"; "Something happened while my mother was giving birth to me"; "Something happened to me after I was born"; and "It is unknown." The first two options were then classified as "genetic," and the last four options were classified as "non-genetic/unknown" for subsequent analyses. Participants were invited to provide details if they marked one of the "Something happened..." categories, however, those responses are not analyzed in this study.

\section{Demographics}

Demographic data were also collected, and included age, gender, ethnicity/race (non-Hispanic Caucasian, Hispanic, African-American, Asian, American Indian/Alaska Native, Native Hawaiian or Other Pacific Islander), cultural affiliation (hearing community, Deaf community, both communities, neither community), type of high school program [hearing-based programs: oral instruction in the classroom (i.e., oral school for the deaf, or a public school without interpreter/support services); Deaf-based programs: signed instruction (e.g., ASL or coded communication in the classroom); mainstream programs: public schools that predominantly provide signed instruction (e.g., ASL or coded communication with interpreter/support services); mixed program (defined as attending two or more of the previously described high school programs)]; highest attained education level (dichotomized as $<$ or $\geq$ undergraduate bachelor's degree); family history of deaf relatives (at least one deaf first or second degree relative/no deaf relatives); student status (yes/no); marital status (married/not married); employment status (employed part- or full-time, unemployed, retired); and income category (in $\$ 15 \mathrm{~K}$ increments).
Data Analysis

Descriptive statistics were produced and reviewed for the presence of outliers and data errors. Demographic characteristics were compared across language groups using analysis of variance (ANOVA) or Chi-square/Fisher's Exact test when examining association between language and a quantitative or categorical variable, respectively. We then conducted a series of bivariate analyses to identify potential demographic confounders with baseline genetics knowledge score in our sample. Specifically, Pearson's product correlation was computed to determine if age at enrollment was associated with baseline knowledge score. ANOVA was used to determine if baseline genetics knowledge was independently associated with sex, type of high school program attended by the participant, education level, family history, student status, marital status, and employment status.

Cultural affiliation was not evaluated as a covariate of genetics knowledge because this demographic variable was very strongly associated with language (Fisher's Exact test, $p<.0001$; see Table 1). Although type of high school program also was very highly correlated with language (Fisher's Exact test, $p<.0001$; Table 1), we examined it as a potential covariate of genetics knowledge because of its potential relationship with educational curricula (Harmer 1999). Highest attained education level also was significantly associated with income $\left(F_{(1,208)}=50.98, p<.0001\right)$. We included only education as a possible covariate in these analyses because inclusion of income decreased the sample size due to missing data on this variable. As there were four genetic counselors and three primary sign language interpreters, we also examined the potential effect of genetic counselor and sign language interpreter on knowledge by performing an ANOVA with genetic counselor (or sign language interpreter) as the independent variable, and difference between pre-test genetic counseling knowledge score and baseline knowledge score as the dependent variable.

To address the main research questions, we first conducted a series of paired t-tests and ANOVAs to determine if pre-test genetic counseling enhanced genetics knowledge outcomes, if there was an association between participants' language and genetics knowledge, and if there was an association between participants' prior beliefs about etiology and genetics knowledge. Post-hoc two-way comparisons were conducted to identify specific group differences using Tukey's HSD test (Box et al. 1978), which controls for Type I experiment-wise error rate. To examine the robustness of these separate analyses, we then performed repeated measures multiple regression analysis to simultaneously examine the effects of pre-test genetic counseling, language, and prior beliefs about etiology on genetics knowledge scores while also taking into account additional demographic variables exhibiting significant 
Table 1 Sample demographics

\begin{tabular}{|c|c|c|c|c|c|}
\hline & Total sample ${ }^{\mathrm{a}}$ & $\begin{array}{l}\text { ASL with } \\
\text { interpreter }\end{array}$ & $\begin{array}{l}\text { ASL + English, } \\
\text { interpreter }\end{array}$ & $\begin{array}{l}\text { English, no } \\
\text { interpreter }\end{array}$ & $p$-value ${ }^{\mathrm{b}}$ \\
\hline Sample Size ${ }^{c}$ & 244 & 158 & 53 & 30 & \\
\hline Average Age (SD), in years & $46.1(15.8)$ & $46.7(16.2)$ & $45.9(14.6)$ & $42.0(15.9)$ & .33 \\
\hline Min & 18.1 & 18.2 & 18.1 & 20.1 & \\
\hline Max & 88.5 & 86.0 & 74.7 & 88.5 & \\
\hline$\%$ Female & $60.3(n=147)$ & $57.6(n=91)$ & $66.0(n=35)$ & $60.0(n=18)$ & .55 \\
\hline \multicolumn{6}{|l|}{ Ethnicity/Race } \\
\hline$\%$ non-Hispanic Caucasian & $79.5(n=194)$ & $77.2(n=122)$ & $90.6(n=48)$ & $70.0(n=21)$ & $.04^{\mathrm{d}}$ \\
\hline$\%$ Hispanic & $10.3(n=25)$ & $12.7(n=20)$ & $1.9(n=1)$ & $13.3(n=4)$ & \\
\hline$\%$ Asian & $8.6(n=21)$ & $9.5(n=15)$ & $3.8(n=2)$ & $13.3(n=4)$ & \\
\hline$\%$ Other $^{\mathrm{e}}$ & $1.6(n=4)$ & $.63(n=1)$ & $3.8(n=2)$ & $3.3(n=1)$ & \\
\hline \multicolumn{6}{|l|}{ Cultural affiliation } \\
\hline$\%$ Hearing community & $7.4(n=18)$ & $.6(n=1)$ & $1.9(n=1)$ & $55.2(n=16)$ & $<.0001^{\mathrm{f}}$ \\
\hline$\%$ Deaf community & $55.8(n=135)$ & $66.9(n=105)$ & $50.9(n=27)$ & $6.9(n=2)$ & \\
\hline$\%$ Both communities & $34.7(n=84)$ & $30.6(n=48)$ & $47.2(n=25)$ & $31.0(n=9)$ & \\
\hline$\%$ Neither community & $2.1(n=5)$ & $1.9(n=3)$ & 0 & $6.9(n=2)$ & \\
\hline \multicolumn{6}{|l|}{ High school program ${ }^{\mathrm{g}}$} \\
\hline$\%$ Hearing-based & $30.5(n=72)$ & $17.2(n=26)$ & $36.5(n=19)$ & $80.0(n=24)$ & $<.0001$ \\
\hline$\%$ Deaf-based & $37.3(n=88)$ & $51.7(n=78)$ & $19.2(n=10)$ & 0 & \\
\hline$\%$ Mainstream & $21.6(n=51)$ & $18.5(n=28)$ & $32.7(n=17)$ & $20.0(n=6)$ & \\
\hline$\%$ Mixed & $10.6(n=25)$ & $12.6(n=19)$ & $11.5(n=6)$ & 0 & \\
\hline$\%$ with undergraduate bachelor or higher degree & $55.1(n=134)$ & $49.4(n=78)$ & $65.4(n=34)$ & $66.7(n=20)$ & .05 \\
\hline$\%$ with deaf first- or second-degree relatives & $54.1(n=132)$ & $57.6(n=91)$ & $47.2(n=25)$ & $46.7(n=14)$ & .29 \\
\hline$\%$ students & $13.6(n=33)$ & $13.4(n=21)$ & $11.5(n=6)$ & $20.0(n=6)$ & .56 \\
\hline$\%$ married & $46.9(n=114)$ & $49.7(n=78)$ & $45.3(n=24)$ & $36.7(n=11)$ & .41 \\
\hline \multicolumn{6}{|l|}{ Employment status } \\
\hline$\%$ part- or full-time & $64.1(n=155)$ & $59.9(n=94)$ & $73.6(n=39)$ & $72.4(n=21)$ & .22 \\
\hline$\%$ unemployed & $19.8(n=48)$ & $21.7(n=34)$ & $11.3(n=6)$ & $20.7(n=6)$ & \\
\hline$\%$ retired & $16.1(n=39)$ & $18.5(n=29)$ & $15.1(n=8)$ & $6.9(n=2)$ & \\
\hline Median income level, in thousands of dollars & $35-50$ & $35-50$ & $50-65$ & $50-65$ & .13 \\
\hline Beliefs, \% genetic & $43.0(n=105)$ & $45.6(n=72)$ & $30.2(n=16)$ & $53.3(n=16)$ & .07 \\
\hline
\end{tabular}

${ }^{\text {a }}$ Some items are missing values for some individuals.

${ }^{\mathrm{b}}$ Statistical significance of comparisons across the three language groups

'Three individuals' language could not be classified into one of the three main groups

${ }^{\mathrm{d}}$ Analysis comparing non-Hispanic Caucasian group to all others

e "Other" category contains African-American $(n=2)$, American Indian/Alaska Native $(n=1)$, and Native Hawaiian or Other Pacific Islander $(n=1)$ ${ }^{\mathrm{f}} n=5$ individuals in the "Neither Community" group were excluded from this analysis due to small sample size

${ }^{\mathrm{g}}$ Hearing-based programs predominantly provide oral instruction in the classroom (i.e., oral school for the deaf, or a public school without interpreter/support services); Deaf-based programs predominantly provide signed instruction (ASL or coded communication) in the classroom; Mainstream programs captures public schools that predominantly provide signed instruction (ASL or coded communication) with interpreter/ support services; Mixed program is defined as attending two or more of the previously described high school programs

association with baseline genetics knowledge score. Finally, we examined interactions between significant main effect variables and pre-test genetic counseling to determine if subgroups of participants showed significantly greater improvement in genetics knowledge after pre-test genetic counseling. Three participants whose language preference was described as "other" were excluded from analyses that included language as a variable due to their small sample size. Analyses were conducted using SAS version 9.1 (SAS Institute, Cary, NC). Repeated measures regression analysis was performed using PROC MIXED procedure in SAS. Statistical significance was set at $\alpha=.05$. 


\section{Results}

Sample Demographics

A total of 271 participants completed the audiology evaluation. Of these, $263(97.1 \%)$ were determined to be eligible to participate in the genetic counseling and testing part of the study, and 248/263 (94.3\%) participated in the pre-test genetic counseling session. Among the 15 eligible individuals who did not participate in the pre-test genetic counseling session, three actively withdrew, three passively declined to continue, and nine were not able to be scheduled after at least one attempt. These 15 individuals were more likely to be male $(p=.03)$, and to use ASL with an interpreter $(p=.03)$, but they did not differ significantly from the 248 eligible individuals who pursued pre-test genetic counseling with respect to age, education level, prior beliefs, or baseline knowledge scores.

Useable data were collected on both the baseline and pre-test counseling questionnaires from 244 individuals (92.8\% of those individuals who were eligible for pre-test genetic counseling following the audiology evaluation). Table 1 illustrates the considerable cultural, linguistic, and other demographic diversity in this sample of 244 deaf and hard-of-hearing participants. Their age at enrollment ranged from $18-89$ years (mean of 46.1 years; $\mathrm{SD}=15.8$ ); both males and females participated, with females comprising $60.3 \%(n=147)$ of the sample. Participants' cultural affiliation included Deaf community $(55.8 \%, n=135)$, hearing community $(7.4 \%, n=18)$, and both communities $(34.7 \%, n=84)$; and their language use when interacting with hearing study staff included ASL with an interpreter $(64.8 \%, n=158)$, ASL and English along with an interpreter $(21.7 \%, n=53)$, English without an interpreter $(12.3 \%, n=30)$, and various forms of coded communication (e.g., Signed English; $1.2 \%, n=3$ ). As expected, participants' language use was significantly associated with the type of high school program attended (Fisher's Exact test, $p<.0001$ ) and with their cultural affiliation (Fisher's Exact test, $p<.0001$ ) (see Table 1). Although there were no expectations about a relationship between language use and the remaining demographic variables, we found that ethnicity/race (Fisher's Exact test, $p=.04$ ) and highest attained education level (Fisher Exact test, $p=.05$ ) differed significantly across the three language groups (see Table 1).

Demographic Variables Associated with Baseline Genetics Knowledge Scores

Significant predictors of baseline genetics knowledge were age $(r=-.29, p<.0001)$, education level (<undergraduate bachelor's degree, mean score $=6.87, \mathrm{SD}=1.67$; $\geq$ undergraduate bachelor's degree, mean score $=8.24, \mathrm{SD}=1.58$; $p<.0001$ ), type of high school attended (hearing-based, mean score $=8.09, \mathrm{SD}=1.64$; Deaf-based, mean score $=$ 7.16, $\mathrm{SD}=1.80$; mainstream, mean score $=8.08, \mathrm{SD}=1.51$; mixed, mean score $=7.08, \mathrm{SD}=1.87 ; p=.0006$ ), family history (yes, mean score $=7.89, \mathrm{SD}=1.71$; no, mean score $=7.32$, $\mathrm{SD}=1.76 ; p=.01$ ), employment status (employed, mean score $=7.82, \mathrm{SD}=1.70 ;$ unemployed, mean score $=7.43$, $\mathrm{SD}=1.81$; retired, mean score $=7.0, \mathrm{SD}=1.77 ; p=.02$ ), and student status (yes, mean score $=8.24, \mathrm{SD}=1.6$; no, mean score $=7.54, \mathrm{SD}=1.75 ; p=.03)$. These variables were included as covariates in the repeated measures regression analyses.

Effect of Pre-Test Genetic Counseling, Language, and Prior Beliefs on Genetics Knowledge Scores

\section{Pre-test Genetic Counseling}

The mean genetics knowledge score in the entire sample at baseline was $7.61(\mathrm{SD}=1.79)$ and after pre-test genetic counseling was $7.92(\mathrm{SD}=1.65)$. There was a statistically significant increase in knowledge score following pre-test genetic counseling (paired $\mathrm{t}_{(239)}=$ $3.45, p=.0007$ ) with an overall mean increase (i.e., effect size) of .3 units.

To determine if improvement in genetics knowledge score was a function of a specific genetic counselor or sign language interpreter, we performed ANOVA with knowledge change as the dependent variable. No association was found between genetic counselor and knowledge change $(p=.78)$, or sign language interpreter and knowledge change $(p=.52)$; therefore these variables were not considered further.

To determine if the improvement in genetics knowledge score might be explained by participants' having the opportunity to obtain genetics knowledge from sources outside of the project prior to the pre-test genetic counseling session, we performed two different analyses. First, we computed the correlation between knowledge change and length of time between completion of the baseline questionnaire (usually completed immediately after the audiology appointment) and completion of the pre-test counseling questionnaire (usually completed immediately following the pre-test genetic counseling session). A positive correlation would indicate that a greater interval between the audiology appointment and the pre-test genetic counseling appointment produced more genetics knowledge and would suggest outside factors could have intervened to explain the observed increase in knowledge after pre-test genetic counseling. However, the correlation was found to be -.125 $(p=.053)$, suggesting a non-significant trend toward genetics knowledge decreasing as time between appointments increased. Second, we compared baseline genetics knowledge scores to knowledge scores computed from the 
"equivalence" questionnaire completed by a subset of 30 participants prior to the pre-test genetic counseling session. Knowledge scores were not found to differ significantly between the baseline questionnaire and the equivalence questionnaire (paired $t_{(29)}=.45, p=.65$ ). Not only do these results strengthen the inference that the pre-test genetic counseling session itself increased genetics knowledge in the sample, but the second analysis also provides evidence for the translational equivalence of the genetics knowledge items between the ASL and English only versions of the questionnaire.

\section{Language}

Genetics knowledge scores were high at baseline for all three language groups, indicating generally good knowledge regarding relevant genetics concepts in this sample prior to meeting with a genetic counselor. There also was an association between mean baseline knowledge scores and language $\left(F_{(2,238)}=13.5, p<.0001\right)$. Genetics knowledge scores were higher for participants who used English without an interpreter (mean $=8.90, \mathrm{SD}=1.32$ ) compared to participants who used ASL and English with an interpreter (mean=7.96, $\mathrm{SD}=7.96$ ), or ASL with an interpreter (mean=7.27, $\mathrm{SD}=1.77$ ). Tukey's HSD indicated that each group mean was significantly different from the others at a Type I experiment-wise .05 level [English without an interpreter group - ASL with an interpreter group score difference $=1.63,95 \%$ CI $(.85,2.42)$; English without an interpreter group - ASL and English with an interpreter group score difference $=.94,95 \%$ CI $(.04,1.84)$; ASL and English with an interpreter group - ASL with an interpreter group score difference $=.70,95 \%$ CI $(.07,1.32)]$. Within-group paired $t$-test analyses revealed that knowledge scores significantly increased after pre-test genetic counseling only for the ASL group $\left(t_{(156)}=2.84, p=.005\right)$, suggesting that knowledge outcomes were particularly enhanced in this language group by pre-test genetic counseling. However, mean genetics knowledge scores after pre-test genetic counseling continued to differ significantly across the three language groups $\left(F_{(2,237)}=32.0, p<.0001\right.$; ASL with interpreter, mean score $=7.61, \mathrm{SD}=1.62$; ASL and English with interpreter, mean score $=8.21, \mathrm{SD}=1.63$; English without interpreter, mean score $=9.13, \mathrm{SD}=1.10$ ). Tukey's HSD again indicated that each group mean was significantly different from the others at a Type I experiment-wise .05 level [English without an interpreter group - ASL with an interpreter group score difference $=1.53,95 \%$ CI $(.79$, 2.26); English without an interpreter group - ASL and English with an interpreter group score difference $=.93,95 \%$ CI (.08, 1.77); ASL and English with an interpreter group ASL with an interpreter group score difference $=.60,95 \%$ CI $(.02,1.19)]$.

\section{Prior Beliefs about Etiology}

There also was a significant association between genetics knowledge and an individual's prior beliefs about why they are deaf. The mean baseline knowledge scores were significantly higher in the group who attributed the reason they are deaf to a genetic explanation compared to the group who attributed the reason they are deaf to nongenetic or unknown causes (mean $=8.24, \mathrm{SD}=1.59$ versus mean $=7.15, \mathrm{SD}=1.73$, respectively, $\left.F_{(1,239)}=24.9, p<.0001\right)$. Within-group paired $t$-test analyses revealed that genetics knowledge scores significantly increased after pre-test genetic counseling only for the "non-genetic belief/unknown" group $\left(t_{(136)}=3.57, p=.0005\right)$, suggesting that knowledge outcomes were particularly enhanced in this group by pre-test genetic counseling. However, mean knowledge scores after pre-test genetic counseling continued to differ significantly between the two belief groups, where those who attributed the reason they are deaf to a genetic explanation had higher genetics knowledge scores than those who attributed the reason they are deaf to non-genetic or unknown causes (mean $=8.38$, $\mathrm{SD}=1.42$ versus mean $=7.60, \mathrm{SD}=1.72$, respectively, $F_{(1,238)}=$ $14.2, p=.0002)$.

\section{Repeated Measures Multiple Regression Analyses}

We then conducted repeated measures multiple regression analysis to simultaneously examine the main effects of pre-test genetic counseling, language, and prior beliefs about etiology on genetics knowledge scores, including as covariates those demographic variables exhibiting significant association with baseline knowledge score (age, highest attained education level, family history, high school attended, employment status, and student status). For these analyses age is dichotomized as either above or below the sample median age of 45.4 years. Even after controlling for potential covariates of genetics knowledge, the main effect of pre-test genetic counseling $\left(F_{(1,228)}=13.82, p=.0003\right)$ was statistically significant, demonstrating significant improvement in genetics knowledge scores after pre-test genetic counseling. In addition, the main effect of language $\left(F_{(2,216)}=6.63\right.$, $p=.002)$, the main effect of prior beliefs $\left(F_{(1,216)}=11.89\right.$, $p=.0007)$, and the covariates age and education were significant predictors of knowledge $\left(F_{(1,216)}=11.66, p=.0008\right.$, $F_{(1,216)}=40.55, p<.0001$, respectively), where knowledge scores tended to be higher among those who used English without an interpreter, believed they were genetically deaf, were younger and had at least an undergraduate 4 year degree. Family history $\left(F_{(1,216)}=.00, p=.96\right)$, high school attended $\left(F_{(3,216)}=.75, p=.52\right)$, employment status $\left(F_{(2,216)}=.10, p=.91\right)$, and student status $\left(F_{(1,216)}=2.12, p=.15\right)$ were not significant predictors of genetics knowledge. Repeating the analysis in the 
larger sample without the non-significant covariates yielded similar results, providing support for excluding non-significant covariates from subsequent analyses. Although ethnic/racial variation was present in this sample, it is not sufficient to allow ethnicity/race to be included as a potential covariate. To address the robustness of the results, we repeated the repeated measures regression analyses with the subset of participants who marked Caucasian as their ethnic/racial category. This analysis yielded similar parameter estimates, providing evidence that the results from the larger sample are robust with respect to race/ethnic heritage.

We next added interaction terms between pre-test genetic counseling and the other four significant main effects (language, beliefs, age, and education) to the repeated measures regression model as a preliminary step to evaluate the potential of pre-test genetic counseling to enhance genetics knowledge scores among subgroups of participants. There was no evidence that pre-test genetic counseling enhanced genetics knowledge outcomes among participants stratified by age $\left(F_{(1,223)}=2.56, p=.11\right)$ or education level $\left(F_{(1,223)}=.03, p=.87\right)$. Moreover, in the context of other covariates of genetics knowledge, there was no longer any evidence that pre-test genetic counseling enhanced knowledge outcomes among participants in a particular language group $\left(F_{(2,223)}=.31, p=.73\right)$. However, there was evidence that pre-test genetic counseling had a more pronounced effect on enhancing genetics knowledge outcomes among the subgroup of individuals who believe they are deaf for non-genetic or unknown reasons (genetic counseling $\mathrm{X}$ prior beliefs interaction term, $\left.F_{(1,223)}=4.12, p=.04\right)$. Thus, in the final model we excluded the interaction terms deemed nonsignificant in the previous analysis, re-ran the repeated measures regression analysis, and confirmed that the main effects of pre-test genetic counseling $\left(F_{(1,227)}=11.73\right.$, $p=.0007)$, language $\left(F_{(2,223)}=12.82, p<.0001\right)$, and prior beliefs $\left(F_{(1,223)}=16.0, p<.0001\right)$, and the interaction between pre-test genetic counseling and beliefs $\left(F_{(1,227)}=4.47, p=.035\right)$ were statistically significant predictors of genetics knowledge, even after controlling for age and education as covariates (see Table 2). Age $\left(F_{(1,223)}=20.29, p<.0001\right)$ and education $\left(F_{(1,223)}=45.59, p<.0001\right)$ also continued to be statistically significant predictors of genetics knowledge (Table 2). Table 3 illustrates the effects of these predictor variables on genetics knowledge by demonstrating the predicted knowledge scores values for the three language groups as a function of prior beliefs.

To further explore the interaction between pre-test genetic counseling and prior beliefs, we conducted analyses in which we compared the percentage of correct responses for each genetics knowledge item across the two prior beliefs groups (Table 4). At baseline, the two groups differed significantly on percentage of correct responses for 7 of the 10 knowledge items (items \# 1, 3, 4, 5, 6, 9,
10). In each case, the "non-genetic belief/unknown" group had fewer correct responses than the "genetic belief" group. We then performed within-group analyses for each item to determine for which items there was statistically significant improvement within a group. We did this by comparing the number of individuals with the pattern of responding correctly at baseline and incorrectly after pre-test genetic counseling $\left(\mathrm{N}_{1}\right)$ to the number of individuals with the pattern of responding incorrectly at baseline and correctly after pre-test genetic counseling $\left(\mathrm{N}_{2}\right)$. Under the null hypothesis of no effect of pre-test genetic counseling $\mathrm{Z}=$ $\left(\mathrm{N}_{1}-\mathrm{N}_{2}\right) /\left(\mathrm{N}_{1}+\mathrm{N}_{2}\right)^{1 / 2}$ is normally distributed, and so a one sided z-test can be used to assess significance. After pre-test genetic counseling, there was a significant increase in the percentage of correct responses in the "non-genetic belief" group for 6 knowledge items (items \# 4, 5, 6, 7, 9, 10). In comparison, after pre-test genetic counseling there were no knowledge items for which the "genetic belief" group demonstrated a statistically significant level of improvement.

\section{Discussion}

\section{Major Findings}

This is the first study to examine the impact of genetic counseling on genetics knowledge outcomes of deaf or hard-of-hearing individuals. Our results demonstrate that deaf and hard-of-hearing individuals' genetics knowledge is enhanced by pre-test genetic counseling. Although knowledge of genetics concepts was relatively high at baseline, there was improvement in knowledge scores after pre-test genetic counseling for participants who used ASL with an interpreter, those who used a combination of ASL and English with an interpreter, and those who used English without an interpreter. These findings suggest that pre-test genetic counseling is important for all deaf or hard-of-hearing individuals and they support provision of health services in a culturally and linguistically appropriate manner to increase deaf individuals' genetics knowledge and comprehension (Middleton et al. 2010b; Withrow et al. 2008; Withrow et al. 2009a). Additionally important, there was no evidence that improvement in genetics knowledge scores could be explained by idiosyncrasies of the study protocol (time between audiology and pre-test genetic counseling sessions) or personnel (genetic counselors, sign language interpreters), further supporting a conclusion that pre-test genetic counseling itself enhanced genetics knowledge outcomes of deaf or hard-ofhearing individuals.

To our knowledge, this study provides the first set of empirical data on baseline genetics knowledge in the deaf population. The sample was linguistically diverse, and language was a significant predictor of baseline genetics 
Table 2 Repeated measures regression analysis: predictors of genetics knowledge, final model

\begin{tabular}{|c|c|c|c|}
\hline Model variable & $\begin{array}{l}\text { Parameter estimate: change } \\
\text { between groups (SE) }\end{array}$ & $\begin{array}{l}\text { Parameter estimate: mean } \\
\text { value by group (SE) }\end{array}$ & $\mathrm{p}$ \\
\hline Pre-test genetic counseling & & & .0007 \\
\hline Before & $-.47(.21)$ & $7.92(.11)$ & \\
\hline After & - & $8.21(.11)$ & \\
\hline Language & & & $<.0001$ \\
\hline $\mathrm{ASL}^{\mathrm{a}}$ with interpreter & $-.61(.21)$ & $7.47(.10)$ & \\
\hline English without interpreter & $.57(.29)$ & $8.65(.24)$ & \\
\hline ASL and English with interpreter & - & $8.08(.18)$ & \\
\hline Prior beliefs about why deaf & & & $<.0001$ \\
\hline Genetic & $.51(.19)$ & $8.41(.15)$ & \\
\hline Non-Genetic/Unknown & - & $7.72(.13)$ & \\
\hline Age & & & $<.0001$ \\
\hline$<45.4$ years & $.75(.17)$ & $8.44(.13)$ & \\
\hline$\geq 45.4$ years & - & $7.69(.14)$ & \\
\hline Education & & & $<.0001$ \\
\hline$<$ Bachelor's degree & $-1.15(.17)$ & $7.49(.15)$ & \\
\hline$\geq$ Bachelor's degree & - & $8.64(.12)$ & \\
\hline Interaction between Pre-Test Genetic Counseling and Prior Beliefs & $.36(.17)$ & & .035 \\
\hline Before Pre-Test Genetic Counseling and 'Genetic' & $.39(.21)$ & $8.35(.16)$ & \\
\hline Before Pre-Test Genetic Counseling and 'Non-Genetic/Unknown' & $-.47(.19)$ & $7.49(.14)$ & \\
\hline After Pre-Test Genetic Counseling and 'Genetic' & $.51(.21)$ & $8.47(.16)$ & \\
\hline After Pre-Test Genetic Counseling and 'Non-Genetic/Unknown' & - & $7.96(.14)$ & \\
\hline
\end{tabular}

${ }^{\mathrm{a}}$ ASL American Sign Language

knowledge scores. Specifically, the results demonstrate that individuals who used ASL, or ASL and English with an interpreter, had lower baseline genetics knowledge scores compared to those who used English without an interpreter. The finding of a lower level of baseline genetics knowledge is not unique to the population of ASL-users who constitute a cultural and linguistic minority group. Rather, this finding is consistent with evidence that ethnic and cultural minority groups tend to have less knowledge of genetics topics and these differences may be attributed to differences in exposure and access to genetic information and referral from health care providers (Derose and Baker 2000; Halbert et al. 2005; Hughes et al. 1997; Kinney et al. 2010; MacNew et al. 2010).

ASL-users experience challenges to acquiring health and science information in their primary and native language through educational curricula, media, internet, and other mechanisms for obtaining incidental information (Harmer 1999). Thus they are likely under-exposed to genetics concepts and terminology. In addition, standardized technical

Table 3 Predicted genetics knowledge scores from the final repeated measures regression model

\begin{tabular}{|c|c|c|c|c|c|c|}
\hline & \multicolumn{3}{|c|}{ Prior Belief: Genetic } & \multicolumn{3}{|c|}{ Prior Belief: Non-Genetic/Unknown } \\
\hline & $\mathrm{ASL}^{\mathrm{a}}$ & ASL + English & English & ASL & ASL + English & English \\
\hline Predicted Knowledge Score at Baseline ${ }^{b}$ & 6.80 & 7.41 & 7.99 & 5.94 & 6.55 & 7.12 \\
\hline Predicted Knowledge Score After Pre-Test Genetic Counseling ${ }^{\mathrm{b}}$ & 6.92 & 7.53 & 8.10 & 6.41 & 7.02 & 7.59 \\
\hline
\end{tabular}

These results are based on a total sample size of 229 subjects (Genetic Prior Beliefs $n=99$; Non-Genetic/Unknown Prior Beliefs $n=130$ ).

${ }^{\text {a ASL }}=$ American Sign Language with interpreter present; ASL + English = combination of American Sign Language and English with interpreter present; English = spoken English with no interpreter present

${ }^{\mathrm{b}}$ predicted values calculated for an individual over 45.4 years of age, with $<$ undergraduate bachelor's degree. Individuals under 45.4 years of age are predicted to have scores that are .752 units higher, and individuals with $\geq$ undergraduate bachelor's degree are predicted to have scores that are 1.15 units higher. Genetics knowledge scores can range from 0 to 10 
Table 4 Responses to genetics knowledge items as a function of prior beliefs

Genetics knowledge item (correct response T/F)

1. Genetics is the only explanation for deafness (F)

2. A hearing couple cannot have a deaf/hard-of-hearing child (F)

3. Connexin-26 related deafness is the only genetic type of deafness (F)

4. Deafness is inherited in some families (T)

5. There is a very high chance that two people (a couple) with connexin-26-related deafness will have deaf/hard-of-hearing children (T)

6. Currently, when a doctor orders a genetic test, it means that the test examines all of the human genes to see if genetics is the reason why a person is deaf/hard-of-hearing $(\mathrm{F})$

7. Genetics might explain why a hearing couple has a deaf/hard-ofhearing child $(\mathrm{T})$

8. A deaf/hard-of-hearing couple could have a hearing child (T)

9. A child might inherit deafness from two hearing parents (T)

10. Genetic testing will always explain deafness in families with more than one deaf/hard-of-hearing family member $(F)$
Prior beliefs about why deaf

Timepoint Genetic $(n=103) \%$ correct Not Genetic/Unknown $(n=137) \%$ correct

$\begin{array}{lcl}\text { Baseline }^{\mathrm{a}} & 79.6 & 67.2^{*} \\ \text { Pre-test }^{\mathrm{b}} & 82.5 & 69.3 \\ \text { Baseline } & 99.0 & 97.8 \\ \text { Pre-test } & 99.0 & 95.6 \\ \text { Baseline } & 71.8 & 55.5^{* *} \\ \text { Pre-test } & 72.8 & 57.7 \\ \text { Baseline } & 100 & 89.1^{* * *} \\ \text { Pre-test } & 95.2 & 94.9^{* *} \\ \text { Baseline } & 91.3 & 76.6^{* *} \\ \text { Pre-test } & 95.2 & 84.7^{* *} \\ \text { Baseline } & 55.3 & 34.3^{* *} \\ \text { Pre-test } & 51.5 & 43.1^{* *} \\ & & \\ \text { Baseline } & 94.2 & 87.6 \\ \text { Pre-test } & 98.1 & 93.4^{* *} \\ \text { Baseline } & 96.1 & 94.9 \\ \text { Pre-test } & 98.1 & 96.4 \\ \text { Baseline } & 92.2 & 81.7^{*} \\ \text { Pre-test } & 93.2 & 88.3^{*} \\ \text { Baseline } & 46.6 & 30.7^{*} \\ \text { Pre-test } & 52.4 & 35.8^{*}\end{array}$

${ }^{\text {a }}$ Statistical significance between the two prior beliefs groups (genetic; non-genetic/unknown) is noted by asterisks in the Baseline row

${ }^{\mathrm{b}}$ Statistically significant improvement with pre-test genetic counseling within a prior beliefs group is noted by asterisks in the Pre-test row

$* p \leq .05 ; * * p \leq .01 ; * * * p \leq .001$

and medical ASL signs are not widely used for many genetics concepts which may also play a role in the challenges deaf or hard-of-hearing individuals face acquiring information regarding genetic mechanisms, genetic etiology, and genetic testing. Overall, the finding that ASL-users demonstrated lower baseline genetics knowledge supports the hypothesized disparity in access to genetic information for deaf or hard-of-hearing individuals whose primary and native language is ASL. This finding also underscores the need for the development and implementation of innovative mechanisms for disseminating genetic information to ASL-users.

Another noteworthy finding is that participants' beliefs about why they are deaf were significantly related to baseline genetics knowledge scores. Specifically, those individuals who did not believe they were genetically deaf had lower genetics knowledge scores. Studies have shown that beliefs about the role of genetics in a condition and degree of family history of a condition can affect genetics knowledge and understanding (Hiraki et al. 2009; Kelly et al. 2004; Wilson et al. 2004). Because connexin-26, the most common genetic explanation of early onset nonsyndromic deafness, predominantly acts in an autosomal recessive fashion, many genetically deaf or hard-of-hearing individuals will be the only deaf person in their family. A lack of familiarity with recessive inheritance may lead individuals without any deaf relatives to discount the possibility of being deaf for genetic reasons. Consistent with this idea, significantly more of the present participants without any first- or second-degree deaf relatives believed they had a non-genetic explanation for being deaf compared to those with a positive family history $(80.4 \%$ vs. $37.1 \%, p<.0001)$. Consequently, individuals without deaf relatives may have less familiarity with general genetics concepts, while those who believe their deafness is genetic may have better knowledge because their empiric experience of their own family history gives them this knowledge directly. Assessing deaf individuals' prior beliefs during pre-test genetic counseling may be important for enhancing genetics knowledge.

Following pre-test genetic counseling, language and beliefs about etiology continued to be significant predictors of participants' genetics knowledge scores. In addition, 
individuals who believed they were deaf due to non-genetic or unknown etiologies showed greater improvement in knowledge scores following genetic counseling than those who believed at baseline that they were deaf for a genetic reason. Specifically, individuals who believed they were deaf due to an unknown or non-genetic etiology showed improvement after pre-test genetic counseling on 6 of the 10 knowledge items covering a variety of genetics topics, including autosomal recessive inheritance, genetic heterogeneity, and genetic testing (Table 4). These results suggest this subset of the sample had limited knowledge regarding different genetics concepts and benefited greatly from a discussion of the etiologies and the chance of being genetically deaf even if no one else in their family is deaf. Notably, about $43 \%$ of the sample believed there were nongenetic reasons for why they were deaf; thus, pre-test genetic counseling provided value in terms of enhancing genetics knowledge for a large proportion of participants.

Age and education level were consistent demographic predictors of genetics knowledge scores in this study. Younger participants and those with more years of formal education had higher baseline knowledge scores, a finding that has been observed in other pre-test genetic counseling studies (Hughes et al. 1997; Kelly et al. 2004; Randall et al. 2001). Pre-test genetic education interventions have been noted to produce pronounced improvement in knowledge outcomes among older and less educated subgroups in a variety of studies and domains (Green et al. 2004; Kelly et al. 2004; Lerman et al. 1997). However, in contrast to other studies, the present results did not find that pre-test genetic counseling had a more pronounced effect on older individuals or those with less education.

This project strived to provide genetic counseling in a manner that was both culturally and linguistically appropriate. Consistent with this aim, a certified project ASL/English interpreter was provided to any participant who opted to have one present during the pre-test genetic counseling session. While genetics knowledge scores improved with pre-test genetic counseling, and changes in genetics knowledge scores did not appear to be related to specific interpreters, it is unclear why ASL-users' genetics knowledge scores trailed behind English-users' genetics knowledge scores following pre-test genetic counseling. It is difficult to determine the role the presence of an interpreter in general may have played in participants' knowledge and understanding during the genetic counseling sessions. The literature supports providing genetic counseling services directly in the client's primary language whenever possible (Betancourt et al. 2003; Weil 2000), and signed language users prefer to consult directly with a signing health professional (Middleton et al. 2010b). Thus, one hypothesis is that ASL-users' genetics knowledge outcomes would be further enhanced if genetic counseling is provided directly in ASL. A comparison of knowledge outcomes when pre-test genetic counseling is provided directly in ASL to knowledge outcomes when pre-test genetic counseling is provided using a sign language interpreter would further illuminate the role of the interpreter in this regard.

\section{Practice Implications}

The results of this study have implications for the provision of clinical genetic counseling for deaf and hard-of-hearing adults in that they support the efficacy of providing services that are both linguistically and culturally appropriate (Withrow et al. 2009a). In addition to previous recommendations (Arnos et al. 1991a, b; Burton et al. 2006; Middleton et al. 2010b; Withrow et al. 2008), genetic counselors providing services to deaf individuals are encouraged to assess not only cultural affiliation and language preference but to also inquire about the individual's beliefs related to why they are deaf. By doing so, the genetic counselor obtains information about how best to provide genetic counseling services to the individual as well as possible indicators of the individual's baseline knowledge of genetics. This information can be particularly important for determining the structure and content of the genetic counseling session, as well as directing communication with the client both in the genetic counseling session (including the utilization of ASL interpreters) and for contact outside of the appointment (e.g., coordination of appointment times through video relay services).

Since many of the practices used during the genetic counseling sessions in this study were simple to implement, they could easily be adapted in a clinical genetics setting. Communication is a critical element to any genetic counseling session, and it can be a particularly important consideration for genetic counselors providing services to deaf individuals. This project used communication devices including videophones (telecommunication devices that allow for video and audio communication) and video relay services (a service that connects a deaf person using a videophone to a hearing person using a telephone through an interpreter) as well as email and instant messaging to communicate with deaf research participants. Although videophones typically are only available to deaf individuals, the other technologies are easily accessible for use in clinic settings. For genetic counseling sessions, the preferred language of the deaf client should take precedence, and a certified ASL interpreter should be made available if the deaf client uses ASL and the genetics professional is not fluent in ASL. However, because there currently is a lack of consensus on standard ASL signs for genetics terminology, it will be important for genetic counselors to probe the deaf individual's understanding of the genetics information to ensure that it has been accurately translated. Furthermore, genetic counselors 
can assist in the training of sign language interpreters in genetics terminology through these clinical encounters and participation in interpreters' professional conferences.

ASL is a visual language. Thus, communication strategies, line of site (e.g., assurance of clear visual space between the client and the genetic counselor), and potential visual barriers should be given careful consideration. During interactions, the genetic counselor should look at the deaf individual instead of looking at the interpreter, even though the deaf individual may be watching an ASL interpreter and, therefore, not looking at the genetic counselor all of the time. Not only does eye contact improve the genetic counselor's ability to read the participant's non-verbal cues, it also conveys that the deaf individual is the focus of attention (not the sign language interpreter), facilitates rapport, and emphasizes the client-centered nature of the genetic counseling session.

Because Deaf individuals communicate visually, visual aids supporting complex genetic concepts that are used in standard genetic counseling sessions may be especially helpful. Instead of simultaneously presenting verbal and visual information, the genetic counselor should pause when reviewing visual aids to give the deaf person time to first watch the interpreter as he/she translates the genetic counselor's verbal explanation, and then to look at the visual aid. In addition, the structure of ideas might be modified slightly for the genetic counseling sessions with Deaf clients, as ideas may be organized and structured in Deaf culture in a way that is different from that of American hearing culture. For instance, in spoken English, it is common for ideas to be presented first as a broad theme that builds upon and leads up to a main point. In Deaf culture and ASL linguistic discourse, it is common to engage in frank talk (Lane et al. 1996), that is, to identify the main point quickly at the beginning of a conversation, followed by more elaboration. When communicating complex genetic ideas, the genetic counselor should communicate the specific intent of the information first and then elaborate. For example, the genetic counselor may wish to bluntly state the main topics of discussion at the beginning of the session prior to providing detailed explanation: "The gene for connexin-26 is a common explanation for why a person is deaf. During this appointment, we will discuss basic genetic concepts, connexin-26 specifically, and the process of genetic testing..." In addition, consideration of Deaf culture may be relevant when considering the genetic counselor's regular rapport building routine. Instead of including rapport building at the beginning of a session, the genetic counselor may wish to include rapport building at the end of the session. While in hearing culture, it is common for conversations to terminate quickly, Deaf clients, may find this rude and often prefer a more prolonged good-bye. The genetic counselor may wish to include time at the end of the appointment for rapport building and an extended goodbye session and utilize time at the beginning for contracting and direct statements about the expected content of the genetic counseling session (Barnett and Franks 2002).

The provision of medical services, including genetic counseling, that are sensitive to culture and language is not always intuitive. For that reason, we recommend genetic counselors and other clinic staff receive cultural sensitivity training and that clinical genetics services seek the input of Deaf and hard-of-hearing individuals regarding how to meet their needs in the clinic setting, including the location of clinics. The success of the Deaf Genetics Project was in part due to the deaf communitybased locations for genetic counseling and testing. Thus, developing ties with local deaf community agencies and exploring the possibility of setting up outreach clinics located in or near these deaf community agencies may enhance uptake of genetics services by deaf individuals. The National Association of the Deaf (www.nad.org), its local chapters, and other deaf organizations are helpful resources in these respects.

\section{Study Limitations and Research Recommendations}

As with any study, there are limitations to this research which may affect the generalizability of the results. First, the demographics of the sample may not be reflective of the general population seeking genetic counseling services. Specifically, their education level was high, with more than half having a Bachelor's degree or higher. Thus, it is likely that individuals who opted to participate in this genetics research project already had a reasonable baseline understanding of genetics concepts which might not be the case for deaf or hard-of-hearing clients seeking genetic counseling services in general. In fact, baseline genetics knowledge scores were high in this sample and the amount of improvement that could be assessed may have been limited by a ceiling effect. Although this limitation suggests that pre-test genetic counseling in a more general clinic population of deaf adults will have a larger effect on improvement of genetics knowledge outcomes, additional research is needed to determine if in fact this is the case. Additionally, the majority of participants self-reported as Caucasian. Although our sensitivity analysis indicated the results were robust with respect to ethnic/racial background, generalizing the findings to deaf individuals of non-Caucasian backgrounds should be done with caution. Furthermore, this study focused on connexin-26 and connexin-30 testing for nonsyndromic deafness. Pre-test genetic counseling for syndromic forms of deafness may address different genetics concepts, different test limitations, and consequently have different effects on genetics knowledge outcomes. 
Another potential limitation is that genetic counseling and genetic testing were provided at no charge to participants, and thus we may have ascertained a biased sample. In the US, it is likely that deaf individuals with health care coverage would have access to genetics services at limited out of pocket costs outside of this study. Thus, it is unlikely that the availability of genetic counseling and genetic testing at no charge to this study population would differ significantly from the out of pocket costs experienced by deaf individuals in a clinical genetics setting in the US, thereby strengthening the generalizability and validity of the results.

This study attempted to standardize the genetic counseling sessions as much as possible, using standard visual aids, consistently discussing key concepts, and providing cultural sensitivity training to the genetic counselors. Evidence that this aim was achieved is provided by the finding that the magnitude of change in participants' genetics knowledge scores did not vary significantly among the four genetic counselors. It is important to recognize, however, that genetic counselors often tailor a genetic counseling session to the client's needs, and concepts that are discussed may be reflective of the client's family history, personal medical history, and primary concerns. Therefore, the knowledge items used in this study may not always have been reflective of the content focus within the pre-test genetic counseling session, which could lead to an inaccurate portrayal of participants' genetics knowledge outcomes. However, because the effect of the tailored nature of counseling is to bias the results toward the null hypothesis of no change, we believe the results of our study are underestimates of the true effect of pre-test genetic counseling on genetics knowledge outcomes. Furthermore, only ten knowledge items were used in this study, and these ten items likely do not capture every genetics concept discussed during genetic counseling sessions. However, these knowledge items were designed to capture some of the key genetics concepts related to genetic testing that we hoped participants would begin to understand following pre-test genetic counseling. Finally, although the results of this prospective, longitudinal study suggest that the culturally and linguistically tailored genetic counseling model enhanced genetics knowledge outcomes in deaf adults, additional research using randomized controlled studies would be needed for more definitive evaluation of this approach.

Certainly, the effectiveness of a genetic counseling session is dependent upon a number of factors, and the genetic information the client understands and retains is only one measure of the efficacy of a genetic counseling session. Information on the chance of recurrence, for example, is often interpreted by clients in the context of their particular situation and may not be recalled as neutral facts (Clarke et al. 1996; Kessler 1989). In addition, it is impossible to provide information on every facet of genetics in one genetic counseling session. Instead, genetic counseling is an often on-going process, and it is likely that a post-test genetic counseling session would further improve clients' knowledge and understanding of medical genetics. Further studies are needed to examine deaf individuals' genetics knowledge and understanding following receipt of genetic test results.

\section{Conclusions}

Due to a complex mixture of individual, interpersonal, and systemic factors, deaf and hard-of-hearing individuals are at risk for suboptimal health care and health disparities (Harmer 1999). As the influence of genetics on medicine continues to expand, understanding of genetic information will become increasingly more relevant to general medical practice and care. While baseline genetics knowledge was shown to be high in this study population, deaf and hard-of-hearing individuals are likely to benefit from genetic counseling services as assessed by improvements in genetics knowledge and understanding. In a variety of populations, access to genetic counseling has been shown to improve medical management (Hadley et al. 2004; Kauff et al. 2008; Rebbeck et al. 2004), impact health outcomes and psychological well being (Gordon et al. 2005; Sankar et al. 2006), improve use of appropriate healthcare resources (Green et al. 2004), decrease psychological distress (Cabrera et al. 2010), and enhance self-knowledge (Gordon et al. 2005). Studies on many of these factors within the deaf population are noticeably lacking, but it is likely that culturally and linguistically appropriate genetic counseling will have similar benefits within the deaf population and contribute to a reduction in health disparities for this group.

In this article, we described a culturally and linguistically tailored approach to the provision of genetic counseling and testing for the deaf population. Important elements of the approach included: input from Deaf and hard-of-hearing individuals; cultural sensitivity training for the genetic counselors; availability of and training in the use of videophone, video relay service, and TTY; training of sign language interpreters in genetics terminology; genetic counseling notebook with visual aids; training genetic counselors how to appropriately work with sign language interpreters; and deaf community-based locations for genetic counseling and testing. Consistent with recent evidence that providing health services in a culturally and linguistically appropriate manner can increase deaf individuals' health knowledge and comprehension, the present findings indicate that culturally and linguistically sensitive pre-test genetic counseling can be effective in improving genetics knowledge for deaf and hard-of-hearing clients. This is the largest sample of deaf adults to participate in a study of 
the impact of genetic counseling and testing for deaf genes on genetics knowledge, attitudes, psychological, and behavioral outcomes within the deaf population and the only study to examine these issues in the context of actual genetic counseling and genetic testing. The large number of ASLusing Deaf individuals willing to participate in this study provides evidence to support the importance of cultural and linguistic sensitivity in the provision of genetic services.

Acknowledgements Thanks to the deaf and hard-of-hearing community of California who participated in this research. This work was supported by the National Human Genome Research Institute (Ethical, Legal, and Social Issues Branch) [R01 HG003871].

Open Access This article is distributed under the terms of the Creative Commons Attribution Noncommercial License (https:// doi.org/creativecommons.org/licenses/by-nc/2.0/), which permits any noncommercial use, distribution, and reproduction in any medium, provided the original author(s) and source are credited.

\section{References}

Arnos, K. S., Isreal, J., \& Cunningham, M. (1991a). Genetic counseling of the deaf: medical and cultural considerations. Annals of the New York Academy of Sciences, 630, 212-222.

Arnos, K. S., Isreal, J., \& Cunningham, M. (1991b). A model program for genetic counseling of the deaf. Annals of the New York Academy of Sciences, 630, 317-318.

Barnett, S., \& Franks, P. (2002). Health care utilization and adults who are deaf: relationship with age at onset of deafness. Health Services Research, 37, 103-118.

Berman, B. A., Guthmann, D. S., Crespi, C. M., \& Liu, W. (2011). Development and testing of an anti-tobacco school-based curriculum for deaf and hard of hearing youth. American Annals of the Deaf, 155, 592-604.

Betancourt, J. R., Green, A. R., Carrillo, J. E., \& Ananeh-Firempong, O., 2nd. (2003). Defining cultural competence: a practical framework for addressing racial/ethnic disparities in health and health care. Public Health Reports, 118, 293-302.

Boudreault, P., Baldwin, E., Fox, M., Dutton, L., Tullis, L., Linden, J., et al. (2010). Deaf adults' reasons for genetic testing depend on cultural affiliation: results from a prospective, longitudinal genetic counseling and testing study. Journal of Deaf Studies and Deaf Education, 15, 209-227.

Box, G. E. P., Hunter, W. G., \& Hunter, J. S. (1978). Statistics for experimenters. New York: Wiley.

Brislin, R. (1970). Back-translation for cross-cultural research. Journal of Cross-Cultural Psychology, 1, 185-216.

Brunger, J. W., Murray, G. S., O’Riordan, M., Matthews, A. L., Smith, R. J., \& Robin, N. H. (2000). Parental attitudes toward genetic testing for pediatric deafness. American Journal of Human Genetics, 67, 1621-1625.

Burton, S., Withrow, K., Arnos, K., Kalfoglou, A., \& Pandya, A. (2006). A focus group study of consumer attitudes toward genetic testing and newborn screening for deafness. Genetics in Medicine, 8, 779-783.

Cabrera, E., Blanco, I., Yague, C., \& Zabalegui, A. (2010). The impact of genetic counseling on knowledge and emotional responses in Spanish population with family history of breast cancer. Patient Education and Counseling, 78, 382-388.

Choe, S., Lim, R. S.-H., Clark, K., Wang, R., Branz, P., \& Sadler, G. R. (2009). The impact of cervical cancer education for deaf women using a video educational tool employing American Sign Language, open captioning, and graphics. Journal of Cancer Education, 24, 10-15.

Clarke, A., Parsons, E., \& Williams, A. (1996). Outcomes and process in genetic counselling. Clinical Genetics, 50, 462-269.

Daly, M. B., Axilbund, J. E., Bryant, E., Buys, S., Eng, C., Friedman, S., et al. (2006). Genetic/familial high-risk assessment: breast and ovarian. Journal of the National Comprehensive Cancer Network, 4, 156-176.

del Castillo, I., Villamar, M., Moreno-Pelayo, M. A., del Castillo, F. J., Alvarez, A., Telleria, D., et al. (2002). A deletion involving the Connexin 30 gene in nonsyndromic hearing impairment. New England Journal of Medicine, 346, 243-249.

Derose, K. P., \& Baker, D. W. (2000). Limited English proficiency and Latinos' use of physician services. Medical Care Research Reviews, 57, 76-91.

Enns, E., Boudreault, P., \& Palmer, C. (2010). Examining the relationship between genetic counselors' attitudes toward deaf people and the genetic counseling session. Journal of Genetic Counseling, 19, 161-173.

Folkins, A., Sadler, G. R., Ko, C., Branz, P., Marsh, S., \& Bovee, M. (2005). Improving the Deaf community's access to prostate and testicular cancer information: a survey study. BMC Public Health, 5, 63.

Gordon, E. S., Gordish-Dressman, H. A., Devaney, J., Clarkson, P., Thompson, P., Gordon, P., et al. (2005). Nondisease genetic testing: reporting of muscle SNPs shows effects on self-concept and health orientation scales. European Journal of Human Genetics, 13, 1047-1054.

Green, M. J., Peterson, S. K., Baker, M. W., Harper, G. R., Friedman, L. C., Rubinstein, W. S., et al. (2004). Effect of a computer-based decision aid on knowledge, perceptions, and intentions about genetic testing for breast cancer susceptibility: a randomized controlled trial. Journal of the American Medical Association, $292,442-452$.

Hadley, D. W., Jenkins, J. F., Dimond, E., de Carvalho, M., Kirsch, I., \& Palmer, C. G. S. (2004). Colon cancer screening practices following genetic counseling and testing for hereditary nonpolyposis colorectal cancer. Journal of Clinical Oncology, 22, 39-44.

Halbert, C. H., Kessler, L. J., \& Mitchell, E. (2005). Genetic testing for inherited breast cancer risk in African Americans. Cancer Investigation, 23, 285-295.

Halbert, C. H., Kessler, L., Troxel, A. B., Stopfer, J. E., \& Domcheck, S. (2010). Effect of genetic counseling and testing for BRCA1 and BRCA2 mutations in African American women: a randomized trial. Public Health Genomics, 13, 440-448.

Harmer, L. (1999). Health care delivery and deaf people: practice, problems, and recommendations for change. Journal of Deaf Studies and Deaf Education, 4, 73-110.

Hiraki, S., Chen, C., Roberts, J., Cupples, L., \& Green, R. (2009). Perceptions of familial risk in those seeking a genetic risk assessment for Alzheimer's disease. Journal of Genetic Counseling, $18,130-136$.

Hughes, C., Gomez-Caminero, A., Benkendorf, J., Kerner, J., Isaacs, C., Barter, J., et al. (1997). Ethnic differences in knowledge and attitudes about BRCA1 testing in women at increased risk. Patient Education and Counseling, 32, 51-62.

Hwa, H., Huang, L., Hsieh, F., \& Chow, S. (2010). Informed consent for antenatal serum screening for Down syndrome. Taiwan Journal of Obstetrics and Gynecology, 49, 50-56.

Israel, J., Cunningham, M., Thumann, H., \& Arnos, K. (1992). Genetic counseling for deaf adults: communication/language and cultural considerations. Journal of Genetic Counseling, 1, 135-153.

Kash, K., Holland, J., Osborne, M., \& Miller, D. (1995). Psychological counseling strategies for women at risk of breast cancer. Journal of the National Cancer Institute Monographs, 17, 73-79. 
Kauff, N. D., Domcheck, S. M., Friebel, T. M., Robson, M. E., Lee, J., Garber, J. E., et al. (2008). Risk-reducing salpingo-oophorectomy for the prevention of BRCA1- and BRCA2-associated breast and gynecologic cancer: a multicenter, prospective study. Journal of Clinical Oncology, 26, 1331-1337.

Kelly, K., Leventhal, H., Marvin, M., Toppmeyer, D., Baran, J., \& Schwalb, M. (2004). Cancer genetics knowledge and beliefs and receipt of results in Ashkenazi Jewish individuals receiving counseling for BRCA1/2 mutations. Cancer Control, 11, 236-244.

Kessler, S. (1989). Psychological aspects of genetic counseling: VI. A critical review of the literature dealing with education and reproduction. American Journal of Medical Genetics, 1989, 340-353.

Kinney, A. Y., Gammon, A., Coxworth, J., Simonsen, S. E., \& ArceLaretta, M. (2010). Exploring attitudes, beliefs, and communication preferences of Latino community members regarding BRCA $1 / 2$ mutation testing and preventive strategies. Genetics in Medicine, $12,105-115$.

Lane, H. (1999). Mask of benevolence: disabling the Deaf community. San Diego: DawnSignPress.

Lane, H., Hoffmeister, R., \& Bahan, B. (1996). A journey into the Deaf-World. San Diego: DawnSignPress.

Lerman, C., Biesecker, B., Benkendorf, J. L., Kerner, J., GomezCaminero, A., Hughes, C., et al. (1997). Controlled trial of pretest education approaches to enhance informed decisionmaking for BRCA1 gene testing. Journal of the National Cancer Institute, 89, 148-157.

MacNew, H., Rudolph, R., Brower, S., Beck, A., \& Meister, E. (2010). Assessing the knowledge and attitudes regarding genetic testing for breast cancer risk in our region of southeastern Georgia. Breast Journal, 16, 189-192.

Middleton, A., Emery, S. D., \& Turner, G. H. (2010). Views, knowledge and beliefs about genetics and genetic counseling among Deaf people. Sign Language Studies, 10, 170-196.

Middleton, A., Turner, G. H., Bitner-Glindzicz, M., Lewis, P., Richards, M., Clarke, A., et al. (2010). Preferences for communication in clinic from deaf people: a cross-sectional study. Journal of Evaluation in Clinical Practice, 4, 811-817.

Orsi, J. M., Margellos-Anast, H., Perlman, T. S., Giloth, B. E., \& Whitman, S. (2007). Cancer screening knowledge, attitudes, and behaviors among culturally Deaf adults: Implications for informed decision making. Cancer Detection and Prevention, 31, 474-479.

Padden, C., \& Humphries, T. (1988). Deaf in America: Voices from a culture. Cambridge: Harvard University Press.

Pal, T., Stowe, C., Cole, A., Lee, J., Zhao, X., \& Vadaparampil, S. (2010). Evaluation of phone-based genetic counselling in African American women using culturally tailored visual aids. Clinical Genetics, 78, 124-131.

Palmer, C. G., Martinez, A., Fox, M., Zhou, J., Shapiro, N., Sininger, Y., et al. (2009). A prospective, longitudinal study of the impact of GJB2/GJB6 genetic testing on the beliefs and attitudes of parents of deaf and hard-of-hearing infants. American Journal of Medical Genetics A, 149A, 1169-1182.

Pieterse, A., Ausems, M., Spreeuwenberg, P., \& van Dulment, S. (2011). Longer-term influence of breast cancer genetic counseling on cognitions and distress: Smaller benefits for affected versus unaffected women. Patient Education and Counseling, Feb 10 [Epub ahead of print].

Professional Standards Committee Registry of Interpreters for the Deaf. (2007). Interpreting in Health Care Settings, from http:// www.rid.org/UserFiles/File/pdfs/Standard_Practice_Papers/ Drafts_June_2006/Health_Care_Settings_SPP.pdf

Randall, J., Butow, P., Kirk, J., \& Tucker, K. (2001). Psychological impact of genetic counselling and testing in women previously diagnosed with breast cancer. Internal Medicine Journal, 7, 397-405.

Rebbeck, T. R., Friebel, T., Lynch, H. T., Lynch, H. T., Neuhausen, S. L., van't Veer, L., et al. (2004). Bilateral prophylactic mastectomy reduces breast cancer risk in BRCA1 and BRCA2 mutation carriers: the PROSE Study Group. Journal of Clinical Oncology, $22,1055-1062$.

Registry of Interpreters for the Deaf. (2005). NAD-RID Code of Professional Conduct, from http://www.rid.org/UserFiles/File/ NAD_RID_ETHICS.pdf

Ross, L. L., \& Berkowitz, M. C. (2008). Academic ASL: It looks like English, but it isn't. Putting the pieces together. Paper presented at the PEPNet Biennial Conference.

Samady, W., Sadler, G. R., Nakaji, M., \& Malcarne, V. (2008). Translation of the multidimensional health locus of control scales for users of American Sign Language. Public Health Nursing, 25, 480-489.

Sankar, P., Cho, M. K., Wolpe, P. R., \& Schairer, C. (2006). What is in a cause? Exploring the relationship between genetic cause and felt stigma. Genetics in Medicine, 8, 33-42.

Schuchman, J. S. (2004). Deafness and eugenics in the Nazi Era. In J. van Eleve (Ed.), Genetics, disability, and deafness (pp. 72-78). Washington, DC: Gallaudet University.

Schwartz, P. J., Spazzolini, C., Crotti, L., Bathen, J., Amlie, J. P., Timothy, K., et al. (2006). The Jervell and Lange-Nielsen syndrome: natural history, molecular basis, and clinical outcome. Circulation, 113, 783-790.

Senghas, R. J., \& Monaghan, L. (2002). Signs of their times: Deaf communities and the culture of language. Annual Review of Anthropology, 31, 69-97.

Steinberg, A. G., Wiggins, E. A., Barmada, C. H., \& Sullivan, V. J. (2002). Deaf women: experiences and perceptions of healthcare system access. Journal of Womens Health (Larchmont), 11, 729-741.

Steinberg, A. G., Barnett, S., Meador, H. E., Wiggins, E. A., \& Zazove, P. (2006). Health care system accessibility. Experiences and perceptions of deaf people. Journal of General Internal Medicine, 21, 260-266.

Sussner, K., Jandorf, L., Thompson, H., \& Valdimarsdottir, H. (2010). Interest and beliefs about BRCA genetic counseling among atrisk Latinas in New York City. Journal of Genetic Counseling, 19, 255-268.

Tamaskar, P., Malia, T., Stern, C., Gorenflo, D., Meador, H. E., \& Azaove, P. (2000). Preventive attitudes and beliefs of deaf and hard-of-hearing individuals. Archives of Family Medicine, 9, 518-525.

Van Deusen-Phillips, S. B., Goldin-Meadow, S., \& Miller, P. J. (2001). Enacting stories, seeing worlds: Similarities and differences in the cross-cultural narrative development of linguistically isolated deaf children. Human Development, 44, 311-336.

Weil, J. (2000). Psychosocial genetic counseling. New York, NY: Oxford University Press.

Wilcox, S. (1989). American deaf culture: an anthology. Burtonsville: Linstock.

Wilson, B. J., Forrest, K., van Teijlingen, E. R., McKee, L., Haites, N., Matthews, E., et al. (2004). Family communication about genetic risk: the little that is known. Community Genetics, 7, 15-24.

Withrow, K. A., Burton, S., Arnos, K. S., Kalfoglou, A., \& Pandya, A. (2008). Consumer motivations for pursuing genetic testing and their preferences for the provision of genetic services for hearing loss. Journal of Genetic Counseling, 17, 252-260.

Withrow, K. A., Tracy, K. A., Burton, S. K., Norris, V. S., Maes, H. H., Arnos, K. S., et al. (2009a). Provision of genetic services for hearing loss: Results from a national survey and comparison to insights obtained from previous focus group discussions. Journal of Genetic Counseling, 18, 618-621.

Withrow, K. A., Tracy, K. A., Burton, S. K., Norris, V. W., Maes, H. H., Arnos, K. S., et al. (2009b). Impact of genetic advances and testing for hearing loss: results from a national consumer survey. American Journal of Medical Genetics A, 149A, 1159-1168. 